\title{
Study on the Teaching Chinese as A Foreign Language from Cultural Perspective of Sinology
}

\author{
Li Wenjing \\ Si Chuan College of Architectural Technology , DeYang 618000,China \\ liwenjinghy@163.com
}

KEY WORDS: Chinese as a foreign language; Sinology; Teaching and Research

\begin{abstract}
In teaching Chinese as a foreign language, culture teaching is an important means to achieve success in language teaching. However, sinology is the most powerful way of Chinese Teaching. The most essence of China's national culture exists in sinology. Sinology should be a top priority in the culture teaching. While teaching the language knowledge, Chinese Language Teachers for Foreigner should be able to point out the meaning of language from a cultural point of view, and use the sinology to guide students to understand the cultural origin behind Chinese. Teaching Chinese as a foreign language cannot be separated from the study of Chinese cultural knowledge and cultural ideas. It can give students a comprehensive understanding of Chinese society as well as ancient cultural traditions by imparting knowledge of Chinese traditional culture. The factors of language system, such as pronunciation, vocabulary, grammar, are rich in traditional Chinese culture in the teaching of sinology. In this article, we discussed the content and significance of sinology teaching in teaching Chinese as a foreign language, and discussed the application and method design of the sinology in teaching Chinese as a foreign language from the point of view of the relationship between Chinese culture and foreign language teaching, as well as the importance of sinology in the cultural teaching of Chinese as a foreign language.
\end{abstract}

\section{Introduction}

We know that interest is the best motivation, no matter what learning or how to learn, Foreign students have a wide variety of aims to learn Chinese ${ }^{[1-4]}$. However, it is undeniable that all of them have a different degree of interest in Chinese culture. China is an ancient civilization with its five thousand years 'splendid culture. Since ancient times, Chinese people pay great attention to the teaching of sinology. Confucius emphasized the importance of Chinese culture education in "the Analects of Confucius ". Confucius put sinology in the position of the most basic education ${ }^{[5-9]}$. This old idea has continued up to the present time. It still has great significance to the present teaching of Chinese as a foreign language ${ }^{[10-11]}$.

As the essence of the Chinese and even the human literature, sinology is not only a kind of language art, but also is the advanced means of communication between people and people in China for thousands of years. It saves thousands of years of information, it carries a rich Chinese culture, and it is a good text for teaching Chinese as a foreign language. The main object of sinology teaching is the advanced stage of Chinese Learners. This advanced stage of the scholars are the foreign students who He had a long time to learn Chinese and to master more than 2500-3500 vocabulary, but also had a solid foundation of modern Chinese skills and more solid culture. In the cultural teaching for foreign students, the degree of 
difficulty is the main problem of teaching Chinese as a foreign language. In the current study of teaching Chinese as a foreign language, the focus on the value of Chinese sinology in teaching Chinese as a foreign language is not sufficient. Although the theme of sinology culture in foreign language teaching has been more and more concerned by scholars and teachers, but there is only a preliminary discussion and the lack of in-depth discussion on the teaching function of sinology culture. There is no overall understanding, analysis and detailed collation of the theory, but more focus on teaching methods.

\section{The Importance of Sinology Culture in Teaching Chinese as A Foreign Language}

Human is a symbolic animal. Human society is not only a simple physical world, but also is a symbolic world. Admittedly, in this symbol world, language is the symbol system of human intelligence. But culture is also the embodiment of human symbol thinking. Culture and language have different effects on the expression of emotion. The research scope of sinology culture can be expanded from the language phenomenon to other social phenomena, such as art, customs, etc. According to the Chinese sinology culture, the expression of the "the statue expresses feeling" is considered as the expression of the ancient Chinese culture. The Chinese symbol scholars put forward the N-level encoding theory by this thesis. In the theory of $\mathrm{N}$-level coding, the Chinese sinology culture is a cultural code in itself. The image which is embodied by the sinology culture is in the first rank of Chinese language "N level coding theory", which has the meaning of "cultural archetype". The "image" in Chinese sinology culture has a corresponding relationship with the "cultural symbol" which is demonstrated in the Western cultural semiotics. Based on the view of Chinese and Western Cultural Semiotics, we can try to use the perspective of Semiotics in the culture of teaching Chinese as a foreign language. In a certain extent, sinology culture reflects the Chinese cultural tradition, thinking mode and value orientation, and the development of sinology culture is relatively mature, the system is relatively perfect, it can be seen as a kind of cultural symbol. Cultural semiotics is the combination of symbolic thinking and cultural phenomena. Chinese scholar Ye Shuxian, he has become the representative of scholars in this field. This research train inherits and draws lessons from the Cultural Semiotics. These are related to the role of sinology as a cultural symbol in terms of cultural expression. The study on the role of sinology in the expression of culture can provide a theoretical basis for this article. It demonstrates the significance of the application of sinology culture to the teaching of foreign language from different aspects, that is, the teaching of sinology is helpful to improve the performance of the foreign language, and it is helpful to promote the understanding of the language.

Because the language is not a panacea, it must be expressed in the field of human beings, there is some non-language which can be expressed but must be expressed in the state. This state is summarized as the spiritual culture of sinology, namely, the inner life. The inner life is a concept which is the inner spiritual essence that the language cannot fully express. First of all, human beings have an inner life, that is a kind of emotional expression based on the group and individual will. Secondly, the existing culture has a natural deficiency in the form of performance, and it cannot fully express the inner life of human. In contrast, Chinese sinology culture and its expression of logic, lack of verbal and visual expression of the inner life of the theory, representative phenomenon is the hexagrams of "Zhouyi". The purpose is to express the culture which cannot be completely explained by 
language, and the concept of "image" to interpret the concept comes from the activities of Chinese ancient times, and which has profound cultural connotation of sinology culture. The sinology seems like boundless, but it has a relatively definite structure and various types of system. It takes "cultural particle" as the minimum basic unit. A large number of interrelated cultural particles are aggregated into the "cultural knot". Then, a large number of interrelated cultural clusters form a "cultural model". At the same time, the cultural ties can also form a "cultural circle" or "cultural zone". In this way, a nation or social culture has formed a unique attribute, the whole can be self-contained development and can spread from generation to generation. The sinology culture is not fragmented and irregular. Each culture has its own cohesion, tradition and appeal.

\section{Analysis on the Application of Chinese Culture in Teaching Chinese as A Foreign Language}

Although the time is the difference between ancient and modern, the location of the difference between China and foreign countries, human beings can resonate with the common culture. What is the reason for this curious coincidence? Some scholars believe that it is because of the similarity between human emotions and emotional characteristics. In other words, the human is at all times and in all countries. They all have "the same feeling". The sinology, which is spread through the ages, expresses the surging thoughts and feelings of "the some things people can understand, but it is difficult to express". For modern people, especially young students, with the life picture scroll slowly spread out, they gradually come to the community. They will encounter a variety of situations. A variety of emotions will be produced between modern people. All kinds of the ups and downs in the study, job, marriage, family, migration and poor, gain and loss is mankind has to face in every era of 'eternal' life lessons, and it can produce roughly similar emotional activities. Back to the practice of teaching Chinese as a foreign language, there is a common problem: the cultural discomfort in the students". As the Italian scholar Umberto Eco pointed out: before we travel around the world, there is a preconception about the world that it comes from our own cultural tradition. The influence of 'background books' is so real, that it can ignore the actual observations of travelers, but introduces and explains everything in his own words. Under the influence of this kind of psychological reaction, the teaching text is especially important. As a cultural country, China has a history of five thousand years. In the time of about two thousand years, generation person of another acting intellectual advance wave upon wave, such people who have read the book or some literary talent, regardless of the monarchs and nobles, or commoner people; whether it is sheltered, or destitute, they are great enthusiasm and energy to learn Chinese culture, they make the treasure house of Chinese culture has accumulated substantial wealth, leaving behind a great number of renowned and excellent works. No matter what age the readers are, where the readers come from, what kind of experience and feelings they have, all of them can be found in the extensive sinology to resonate with the text. Compared with other countries or nations, the uniqueness of Chinese sinology culture is the ideographic characteristics of Chinese language and characters, it is different to the most significant features of other languages, also is a difficult point in the teaching of foreign Chinese culture. This feature of Chinese characters is reflected in Chinese culture; every word, every word, it has a rich implication.

To make an image of metaphor, a Chinese culture article seems to contain a file 
compression package with huge amount information. It seems the volume is small, but when you extract it, you will find that it can release the amazing amount of information. It represents the highest degree of the beauty of Chinese characters. In other words, sinology culture teaching can guide students to embark on a "convenient passage", we can most quickly and most deeply appreciate the beauty of Chinese language and writing.

In the application of traditional culture in the process of teaching, we mainly grasp the three principles. The first one is based on the existing research results, we carry out the Cultural Decoding in different teaching objects, we carry out a re combination in the teaching content; The second is rendered by a large number of the classic works, it guides students hands-on experience, it can enhance the fun of the classroom, increase classroom participation, promote cultural understanding to Chinese sinology. Third, it integrates culture teaching and other teaching plates, and strives to realize the mutual borrowing of resources and cultural series.

\section{The Design of Chinese Culture in Teaching Chinese as A Foreign Language}

\subsection{Story of Knowledge about}

“Tell Chinese stories well, spread Chinese voice well”, this is the request of $\mathrm{Xi}$ Jinping for the international communication of Chinese culture in the national propaganda and ideological work conference. Since “A bite of China” swept the country, the behavior of conveying thinking orientation, values, and cultural position by way of telling stories has become a common occurrence. And story expression of the new concept and the new category for the fusion of China and foreign countries has been fully recognized from the national level. The process of information transmission is actually the process of the symbolic issue, interpretation and reception, while the symbol itself can be regarded as a kind of text. Zhao Yiheng believes that the symbolic text can be divided into two categories: the one is the narrative text to describe the characters and changes; the other one is the descriptive text without being involved in the characters and changes, which occupies a large proportion in the symbolic text. In the interpretation of the narrative text, narrative turn theory by insisting on the storytelling narrative is theory branching of narrative semiotics and theoretical thought dating from narratology and symbolic learning collision. In the fields of medicine, physics and so on, telling stories has become an effective way to turn theory into practice. It is human nature to like to listen to the story, and story narration is one of the most important means of communication. Throughout "the development of the Chinese " 28 copies, Chinese traditional cultures are mostly stories contained in the text. Editor explores the charm of Beijing opera in the dialogue, tells the famous painter's daily hobbies, or tells the relationship between traditional art and a city, a famous person, which is easy to read and understand. This will not only be able to get rid of blunt academic lectures, but also integrate the traditional art into the topic of the text, which can stimulate students' interest, be in accordance with the basic principles of the narrative, and respect the basic laws of communication.

So aiming at the application of traditional culture in the language teaching, we still need to use the narrative story, increase the application of traditional Chinese culture in the daily life and the cultural orientation and way of thinking behind it, and 
summarize it as a vivid story. In order to dilute the academic color, it will achieve a better communication effect. In the narrative language, we should refer to the present involved in Beijing opera, calligraphy, and traditional Chinese culture in teaching and change the narrative context, so as to conform to overseas students' the language habits and ways of thinking. By story teaching methods, we can deepen their understanding of Chinese cultures and traditional cultures. Being nested knowledge in the story is not only to enhance the course of interest to achieve the purpose of entertaining, but also it is conducive to the optimization of narrative means and enhance the communication effect to achieve the purpose of using the world's words to tell Chinese stories.

\subsection{Cultural Interpretation of Philosophy}

Under cultural interpretation of Philosophy of the current foreign language teaching system, relevant universities have opened courses with academic meaning, such as Chinese Philosophy, Chinese history, and Chinese ancient thought in middle and advanced teaching, so as to make the overseas students understand the Chinese traditional ideology and development context in the courses, which are the introductions of the basic national conditions, cultural background and professional knowledge no longer, while with the meaning of academic research.

This paper argues that, in taking traditional Chinese culture as the theme of teaching Chinese as a foreign language, teachers can teach Chinese traditional culture's basic Confucian, Taoism and the legal thought to the students with higher language level, which not only allows students to have an intuitive understanding of the ancient Chinese thought, but also brings up their abilities of using philosophical common sense to explain cultural imagination. Referring to the relevant theories of semiotics, the culture of traditional Chinese culture in the "object" and "interpretation" of the symbol reflects the value orientation of traditional Chinese culture and the way of thinking. There is a strong sense of life, tradition of advocating perfect and advocating axial symmetry in Chinese culture. At first, there is a sense of life in Chinese culture, which is mainly embodied in three aspects of the concept of reproductive worship, everything with spirit and the pursuit of the times. Firstly, the life consciousness of Chinese culture is embodied in the concept of reproductive worship. As far as the basic symbol of constituting Chinese culture is concerned, there are a lot of genital symbols and its variant existing, such as diamond shaped patterns, crescent patterns, two vertical lines, word Shou lines, and cloud patterns, which are on behalf of the basic indicator of the life consciousness to make the traditional image be the representative of strong reproductive capacity. Secondly, Chinese culture is embodied in the concept of everything with spirit. In traditional Chinese thinking, everything in the world has the mind and soul, so heaven and earth is considered to have the individual life of the independent personality, which is willing to be the theme of performance for the anthropomorphic depiction of nature, animals and plants. Red-crowned crane is wandering in the streams, and lofty mountains are shaded under the sunset, which glows like a fairy - like scene. Compared with the real natural scene, 
there is a clear interpretation of the color and the subjective tendency, not the true natural geographical features, but it is full of fantasy color of the gods, so that it has the characteristics of life. Thirdly, life consciousness of Chinese culture is embodied in the tracking and tracing of the times. It reflects the life tension of looking forward to the new, respecting for nature and pursuit of happiness, which shows the value orientation of Chinese people advocating perfect and looking forward to the reunion of the times. The characteristics of symmetries for left and right, top and bottom on presentation of times works reflect the aesthetic and the attitude of life of Chinese advocating axial symmetry.

\section{5 conclusions}

In this paper, sinology culture is regarded as a cultural symbol of Chinese cultural tradition, thinking mode and value orientation. In the theoretical and practical aspects, this paper discusses the application of Chinese culture in teaching Chinese as a foreign language. Then, according to the relevant theory, application analysis and application design are carried out, this paper expounds the reasons, the research topic, the purpose and the significance of the foreign language teaching. And this paper describes the concept and related literature on the core topic of teaching Chinese as a foreign language. Chinese sinology culture is a kind of cultural symbol, which reflects the Chinese cultural tradition, thinking mode and value orientation, which is in line with the development direction of the teaching of Chinese as a foreign language.

\section{Reference :}

[1] Gao Yande Li gq Susan. Foreigners to learn and use Chinese situation investigation and study report [M]. Beijing: Beijing language college press, 1993.

[2] peng-cheng gong. The history of literary criticism in China [M]. Beijing: Peking University press, 2008.

[3] mankind. Aspects of cross-cultural communication [M]. Shanghai: Shanghai foreign language education press, 1999.

[4] mankind. Culture and communication [M]. Beijing: foreign language teaching and research press, 1994.

[5] huang hq. Think about the Chinese character culture [j] GengLongMing editor. Chinese culture and the world. Shanghai: Shanghai foreign language education press, 1998.

Kojiro yoshikawa [6], Sun Changwu. Du fu's poetry and the poetry [M]. Tang dynasty literature periodicals series 7, 1986.1.

Kojiro yoshikawa [7], Chen Shunzhi Xu Shaozhou. A glimpse of Chinese literature [M]. Chengdu: sichuan people's publishing house, 1987.

New, etc. [8] Jia Yu cross-cultural communication studies (first) [M]. Beijing: higher education press, 2009.

Sequel to [9] Jin Huikang. Cross-cultural communication translation [M]. Beijing: China translation and publishing house, 2004.

[10] Li Runxin. Second culture teaching and second language teaching [M]. Sze-yuan Chou editor. Teaching Chinese as a foreign language and culture. Beijing: Beijing language and culture university press, 1998.

[11] Li Zhu li-ping jiang. How to teach foreigners to study Chinese [M]. Beijing: Beijing 
language and culture university press, 2008.11. 